\title{
Presuposisi dan Metode Yesus dalam Menyampaikan Pendapat: Sebuah Pedoman bagi
}

Para Akademisi

\author{
Deflit Dujerslaim Lilo \\ Sekolah Tinggi Agama Kristen Negeri Toraja, Tana Toraja, Sulawesi Selatan \\ ddujerslilo@gmail.com
}

\begin{abstract}
The Freedom of speechis the human rights of every human being.This freedom must be implemented responsibly with based on the right of thinking, good intentions and goals, and attention tothe rules of thingking. This article examines how Jesus underlies and builds His paradigm and the method that He used to tell His arguments to others.By using a descriptive analysis method and hermeneutic approach to the narratives in the Gospels, it can be concluded that Jesus toldHis argumentby using a logical and comprehensive paradigm and method, so that it could be used as a guidlinefor the academics.
\end{abstract}

Keywords: argument; Jesus' teaching; opinion; presupposition

\begin{abstract}
Abstrak: Kebebasan berpendapat merupakan hak asasi setiap manusia. Kebebasan ini harus dilakukan secara bertanggung jawab dengan berlandaskan pemikiran yang sehat, maksud dan tujuan yang baik, serta memperhatikan aturan-aturan penalaran. Artikel ini meneliti bagaimana Yesus mendasari dan membangun paradigma berpikir-Nya serta cara yang digunakan-Nya untuk menyampaikan pendapat kepada orang lain. Menggunakan metode analisis deskriptif serta pendekatan yang hermenutis pada narasi-narasi di kitab-kitab Injil, dapat ditarik kesimpulan bahwa Yesus menyampaikan pendapat dengan menggunakan paradigma dan metode yang logis dan komprehensif, sehingga dapat dijadikan sebagai suatu contoh bagi para akademisi.
\end{abstract}

Kata Kunci: argumentasi; pendapat; pengajaran Yesus; presuposisi

\begin{tabular}{llll}
\hline Article History : & Received: 15-03-2018 & Revised: 14-05-2018 & Accepted: 12-06-2019
\end{tabular}

\section{Pendahuluan}

Perilaku menyampaikan pendapat di muka umum seringkali mengakibatkan dampak yang kontras. Contoh beberapa waktu silam seorang bernama Rocky Gerung cukup menarik perhatian publik. Ada yang menganggap ide-ide dan argumen-argumennya merupakan sebuah refleksi akademik yang kritis, karena kepiawaiannya dalam mengemukakan pendapat. Namun, tidak sedikit pula yang menganggap Rocky Gerung menggunakan kemampuannya tersebut pada porsi yang salah. Belakangan, diskusi 
publik dengan tema "Menolak Pembusukan Filsafat" pun diselenggarakan. ${ }^{1}$ Forum ini dimulai dengan pembacaan surat pernyataan sikap yang dengan tegas meminta agar seni berpikir dan berargumen tidak disalahgunakan menjadi suatu kepandaian berbicara ala sofisme yang sekilas terlihat benar dan meyakinkan namun ternyata mengandung tipu muslihat yang ditujukan untuk menuai keuntungan semata.

Di dalam kekristenan sendiri, kehadiran dan sumbangsih Yesus Kristus dalam menanamkan contoh pengungkapan ajaran dan pendapat di muka umum juga tidak dapat dipandang sebelah mata. Semasa hidup di dunia, Ia berkeliling dari satu tempat ke tempat lain, berjumpa dan bersosialisasi dengan orang-orang di sekitar-Nya. Dalam perjumpaan itu, Yesus turut mendakwahkan ajaran, perintah, dan larangan kepada siapa pun yang mendengar-Nya. Tidak dapat dipungkiri bahwa Yesus juga memiliki seni berpikir dan berargumen saat mengajar dan menyampaikan pendapat.

Kemampuan Yesus dalam mengajar membuat banyak orang takjub. Melihat-Nya sebagai sosok yang istimewa, beda dari pemimpin agama pada umumnya. Alkitab berkali-kali menyatakan betapa kagumnya orang-orang yang mendengar Yesus setelah Ia selesai mengajar dan atau memberi pendapat (Mat. 7:28-29; Mrk. 1:22, 27; 6:2; 11:18; Luk. 4:32-36). Namun ada juga yang mengkritik, menolak dan berupaya menyingkirkan-Nya karena apa yang telah Ia ajarkan dan lakukan atau karena mengetahui latar belakang kehidupannya.

Lalu, apakah kecakapan-Nya dalam berkomunikasi (yang membuat orang-orang di satu sisi takjub dan di sisi lain benci) sama seperti yang dilakukan oleh Rocky Gerung dan atau kaum Sofis? Penelitian ini mencoba menemukan bagaimana paradigma dan metode Yesus dalam mendasari, membangun, dan menyampaikan ajaran-Nya. Menemukan (paling tidak) contoh dari kerangka pemikiran dan cara Yesus mengkomunikasikan ajaran dan pendapat kepada para murid khususnya dan okhlos pada umumnya untuk dijadikan pedoman bagi para akademisi.

\section{Metode Penelitian}

Penelitian ini menggunakan metode kualitatif yang mendeskripsikan dan menganalisis berbagai literatur. Metode deskriptif digunakan untuk menggambarkan konstruksi presuposisi Yesus yang melatarbelakangi pengajaran dan pendapat-Nya. Presuposisi yang dimaksud di sini adalah latar belakang pemikiran yang dapat dikenal juga dengan istilah pra-asumsi atau paradigma. Namun, presuposisi tidak termasuk pertanyaan, perintah atau permintaan. Sedangkan, analisis digunakan untuk menelaah secara hermeneutis dan logis tentang bagaimana Yesus menggunakan retorika dan propaganda dalam setiap pengajaran-Nya serta meneliti sejauh mana konsistensi Yesus pada prinsip, perkataan, dan tindakan-Nya. Metode observasi digunakan mengamati

\footnotetext{
${ }^{1}$ Simak video diskusi: Dokas Alumni STF Driyarkara, "Diskusi Publik: Menolak Pembusukan Filsafat", https://youtu.be/PqQLv7Z3QWM; diakses 14 Februari 2019.
} 
bagaimana Yesus menyusun presuposisi-Nya dan menggunakan retorika serta propaganda dalam menyampaikan pengajaran.

\section{Presuposisi Yesus}

Yesus, sebagai seorang manusia yang berkomunikasi atau berargumentasi dengan orang banyak (okhlos) di sekitar-Nya tentu memiliki atau berpegang pada suatu presuposisi. Dasar pijakan yang dimiliki-Nya tidak jarang bertentangan dengan orangorang di sekitar-Nya seperti orang-orang Farisi, ahli-ahli Taurat, para Saduki, masyarakat pada umumnya, atau bahkan dengan para murid-Nya sendiri. Hal ini tampak dalam pengajaran-pengajaran atau perdebatan-perdebatan-Nya dengan mereka. Apa yang Yesus gunakan sebagai presuposisi yang melandasi pengajaran-Nya? Bagaimana Yesus membangun argumentasi-Nya pada paradigma tersebut? Untuk menjawab dua pertanyaan tersebut, saya akan menggunakan beberapa contoh yang terdapat dalam kitab-kitab Injil Sinoptik dan Injil Yohanes.

\section{Injil Sinoptik}

Sepanjang Injil Sinoptik, narasi-narasi tentang Yesus yang mengajar, berargumentasi, dan atau sekadar berkomunikasi dengan sesama dipaparkan secara gamblang. Untuk mengajar, berargumentasi, dan berkomunikasi, Yesus tentu berpijak pada presuposisi tertentu. Saya jabarkan secara runut di bawah ini. Pertama, presuposisi Yesus yang paling mendasar adalah bahwa kesadaran dan pengakuan-Nya sendiri tentang kehadiran dan semua hal yang Ia alami dan kerjakan di dunia adalah penggenapan janji dan kehendak Allah yang telah tertulis dan dinyatakan oleh para nabi yaitu "untuk mewujudkan tanda-tanda datangnya Kerajaan Allah" (Mat. 5:17; bdk. Mat. 1:22; 2:15, 17, 23; 3:15; 4:14; 8:17; 12:17; 13:14, 35; 21:4; 26:56; 27:9; Mrk. 14:49; 15:28; Luk. $4: 31 ; 18: 31 ; 21: 22 ; 22: 37 ; 24: 44) .^{2}$

Kedua, alasan kedatangan Yesus ke dunia mempresuposisikan Injil Kerajaan Allah yang berisi rencana karya keselematan Allah bagi orang Israel dan bangsa-bangsa lain (Mrk. 1:38; 13:10; Luk. 4:43). Injil ini menuntut pertobatan dan percaya dari orangorang yang mendengarnya (Mrk. 1:15). Injil Kerajaan Allah ini adalah Injil tentang Yesus sendiri (Mrk. 1:1): pribadi dan karya-Nya. Berdasarkan alasan tersebut maka Yesus mengarahkan perhatian-Nya pada pemberitaan dan pengajaran Injil di mana pun Ia pergi (Mat. 4:23; 9:35; 11:1; Mrk. 1:14-15, 39; Luk. 4:44; 8:1; 20:1). Yesus juga selalu menyertakan pemberitaan Injil dengan tindakan-tindakan sosial-kemanusiaan (Mat. 4:23; 9:35; Mrk. 1:9; Luk. 8:1-3; 9:6). Menariknya, Yesus juga menekankan betapa penting dan bermanfaatnya Injil sebagai tanda kepenuhan zaman, pengingat akan peristiwa keimanan, dan janji anugerah keselamatan yang diberikan (Mat. 20:17-19; 24:14; 26:13; Mrk. 8:35; 10:29; 13:10; 14:9; Luk. 18:31-34). Bahkan Yesus juga memilih,

${ }^{2}$ Albertus Sujoko, Identitas Yesus \& Misteri Manusia, Ulasan Tema-Tema Teologi Moral Fundamental, cetakan ke-5 (Yogyakarta: Kanisius, 2013), 31. 
menetapkan, memperlengkapi dan memberikan amanat kepada para murid untuk memberitakan Injil (Mat. 10:5-15; 28:18-20; Mrk. 3:13-15; 16:20; Luk. 9:6; Kis. 1:8).

Ketiga, presuposisi Monoteisme Yesus dinyatakan melalui argument-Nya tentang hukum yang terutama yaitu: "Kasihilah Tuhan, Allahmu, dengan segenap hatimu dan dengan segenap jiwamu dan dengan segenap akal budimu." (Mat. 22:37; band. Ul. 6:5). Yesus mengutip pidato Musa dalam Ulangan 6:4 yang sekaligus merupakan Syema (bahasa Ibrani = 'Dengarlah') bangsa Israel. Dalam pidato ini Musa menyampaikan perintah ini dengan tujuan agar bangsa Israel "tetap percaya dan setia kepada Tuhan Allah yang telah memilih dan menyelamatkan mereka."3 Yesus menggunakan presuposisi yang sama untuk menegaskan perihal mengasihi Tuhan yang esa (ekhad) dengan hati, jiwa, dan akal budi yang utuh atau tidak terbagi-bagi.

\section{Injil Yohanes}

Injil Yohanes sering disebutkan sebagai kitab Injil yang lebih dogmatis dibanding ketiga Injil Sinoptik. Pada kitab ini, dapat dilihat ajaran-ajaran Yesus yang lebih padat dan keras. Kitab ini lebih banyak mencatat tentang pengakuan dan kesaksian Yesus tentang diri-Nya saat berargumentasi. Lalu, presuposisi apa yang berada dibalik pengajaran dan argumentasi Yesus di dalam Injil Yohanes?

Pertama, hal yang paling mendasar adalah bahwa Yesus datang dengan menyatakan diri sebagai penyelamat manusia atas dasar kasih Allah (Yoh. 3:16-17). Oleh sebab itu, siapa pun yang mendengar dan percaya akan menerima kehidupan kekal sebaliknya yang tidak percaya akan dihukum (Yoh. 3:18-21; 5: 19-47; 8:24; 10:28). Yesus juga menggunakan latar belakang pemikiran ini untuk mengajarkan kepada para muridNyadan orang-orang di sekitar-Nya tentang betapa penting upah yang akan diperoleh karena percaya kepada-Nya (Yoh. 7:38). Kasih Allah tersebut adalah kasih yang adil karena menyelamatkan yang percaya dan menghukum yang tidak percaya, menyediakan tempat di surga bagi yang percaya (Yoh. 14:1-14), dan yang menuntun umat-Nya untuk bertekun dalam menjalani suka-duka kehidupan melalui Roh Kudus yang dijanjikan (Yoh. 14:15-31; 16:1-33). Kasih Allah yang menyelamatkan juga merupakan dasar dari percaya. Menurut Yesus, percaya kepada kasih Allah sama dengan percaya kepada-Nya (Yoh. 17:2-3).

Akan tetapi, kasih Allah tidak hanya menjadi dasar kepercayaan kepada Yesus. Yesus juga menggunakan presuposisi ini untuk mengajarkan bagaimana umat-Nya mengasihi dengan menuruti perintah-Nya (Yoh. 14:15) dan bagaimana umat-Nya meneladani-Nya saat mengasihi sesamanya (Yoh. 13:31-35; 15: 9-17). Dalam hal ini, kasih Allah yang berinisiatif dalam bertindak secara aktif menjadi landasan manusia untuk mengasihi Allah dan sesamanya.

Kedua, Yesus menggunakan ungkapan "Aku adalah" atau "Akulah" ( $\varepsilon \gamma \omega \varepsilon \iota \mu)$ untuk menyatakan presuposisi-Nya sebagai Allah. Ungkapan ini bukan sekadar ungkapan

\footnotetext{
${ }^{3}$ David L. Baker, Mari Mengenal Perjanjian Lama (Jakarta: BPK Gunung Mulia, 2008), 44.
} 
biasa sebab dengan menggunakan frasa tersebut, Yesus menyatakan diri-Nya sejajar atau sama dengan Allah yang menyatakan diri-Nya kepada Musa. Injil Yohanes mencatat bahwa Yesus menggunakan ungkapan tersebut sebanyak tujuh kali saat Yesus berbicara tentang: 'roti hidup' (Yoh. 6:35), 'terang dunia' (Yoh. 8:12), Ia adalah 'pintu' (Yoh. 10:7), 'gembala yang baik' (Yoh. 10:11), diri-Nya adalah 'kebangkitan dan hidup' (Yoh. 11:25), 'Akulah jalan dan kebenaran dan hidup' (Yoh. 14:6), dan 'pokok anggur yang benar' (Yoh. 15:1).

Praanggapan Yesus ini menjadi pijakan bagi-Nya untuk menyatakan peran keilahian-Nya atas umat-Nya. Guthrie menjelaskan peran ini dengan berpendapat: “Dalam setiap hal, 'Aku adalah' menjelaskan peran-peran tertentu dari Yesus, yaitu menguatkan, menyinari, mengakui, memelihara, memberi hidup, membimbing dan membuat produktif." 4 Sebenarnya masih terdapat frase "Akulah Dia" yang diucapkan Yesus untuk menunjuk diri-Nya secara langsung. Misalnya, dalam Yohanes 4:26; 8:24, 28; 13:19; dan 18:5, 6, 8 di mana Yesus menghubungkannya dengan perihal menyatakan identitas-Nya serta akibat dari kepercayaan kepada-Nya.

Yesus sendiri memberikan penegasan dalam ungkapan ini tentang diri-Nya sebagai Logos yang adalah Terang itu, Sumber Terang, dan Terang yang menciptakan (Yoh. 1:410). Bahkan, ketujuh ungkapan "egō eimi" ini menjadi lebih berarti saat Yesus mengatakan bahwa "Aku berkata kepadamu, sesungguhnya sebelum Abraham jadi, Aku

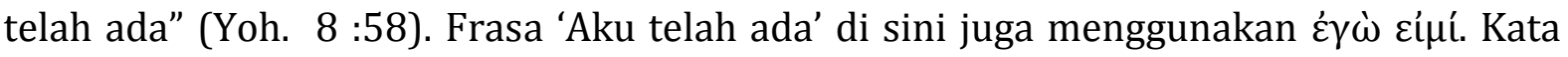

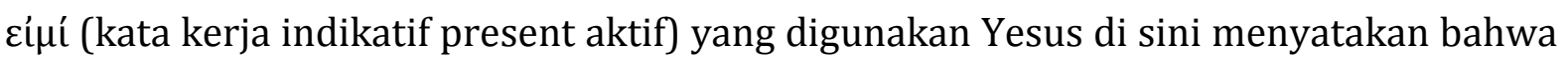
Ia telah ada sebelum, selama, hingga setelah Abraham ada dan aspek keberadaan-Nya adalah aspek yang aktif bertindak secara terus-menerus atau tidak tertentu atau tanpa batas. Frasa ini pun sejajar dengan frase yang digunakan dalam Perjanjian Lama saat Allah menyatakan diri-Nya.

Menurut Guthrie, ungkapan 'Aku adalah' itu digunakan dalam PL sebagai penggambaran Allah. Dalam Keluaran 3:14, Allah menyebut diri-Nya kepada Musa sebagai "Aku adalah Aku", yang memberikan pengertian khusus ilahi pada ungkapan 'Aku adalah" itu. Jika Yesus mengingat maksud ungkapan ini, hal ini akan menyoroti ungkapan 'Aku adalah' yang dicatat dalam Injil Yohanes. ${ }^{5}$

Dalam Perjanjian Lama, Allah menyatakan diri sebagai 'eheyeh 'asyer 'eheyeh

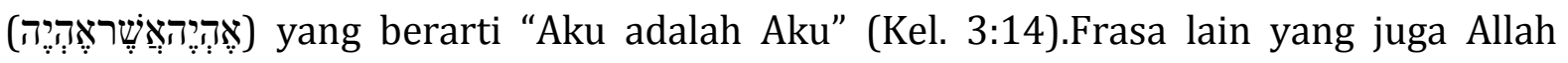
gunakan untuk menyatakan diri adalah אִנִי־דוּוּא (Ani Hu) yang berarti "Aku ada", "Akulah Dia". Misalny; a dalam Yesaya 14:4; 43:10, 13; 46:8; 52:12 di mana frase "Ani Hu" hanya digunakan khusus oleh YHWH sedangkan jika hanya kata "Ani” (aku ada), maka tidak

${ }^{4}$ Donald Guthrie, Teologi Perjanjian Baru 1: Allah, manusia, Kristus (Jakarta: BPK Gunung Mulia, 2008), 375.

5Ibid. 
digunakan untuk penyataan diri-Nya. Menyimpulkan pendapatnya tentang penggunaan frase Ani Hu, David M. Ball mengutip pandangan P.B. Harner sebagai berikut:

Frase ani hu dalam Deutero-Yesaya senantiasa diucapkan oleh Yhwh. Pernyataan ini hanya dapat diucapkan oleh Allah sendiri. Jika ada orang lain yang mengungkapkan kata-kata ini, maka ia menyombongkan dirinya, mencoba menyamakan dirinya dengan Yhwh, atau menggantikan-Nya. Salah satu contoh untuk ini terdapat dalam Yesaya 47:8,10 di mana Babel dengan sombong berkata 'Aku ada, tiada yang lain di sampingku!.'6

Jadi, jelas di sini bahwa Yesus menggunakan presuposisi ini dengan sangat apik untuk mendukung klaim diri-Nya sebagai Allah. Yesus dan Bapa adalah satu (Yoh. 10:30). Orang-orang Yahudi tentu menolak dan menuduh Yesus sebagai penghujat bahkan berupaya membunuh-Nya karena menyamakan diri dengan Allah (Yoh. 8:59).

Apakah Yesus sebagai Allah perlu mengatakan "Aku adalah Allah" untuk membuktikan bahwa Dia adalah Allah sehingga akhirnya semua orang kemudian percaya Dia adalah Allah? Atau, justru Yesus hanya perlu mengaku atau menyebut diriNya "Anak Manusia" untuk membuktikan bahwa Ia bukan hanya Allah yang sejati tetapi juga manusia seutuhnya. Akan tetapi, jika memang mereka menuntut Yesus harus mengatakan bahwa Dia adalah Allah, maka ungkapan $\varepsilon \gamma \hat{c} \varepsilon \dot{\mu} \mu$ íseharusnya telah dapat menjawab keraguan tersebut.

Ketiga, saat Yesus berbicara tentang dasar dari segala yang Ia ajarkan dan lakukan, Yesus merujuk pada kebenaran Allah (Yoh. 8:40). Apa yang Yesus katakan dan lakukan adalah sebuah kebenaran dan bukan dusta (Yoh. 8:44-46). Kebenaran Allah tampak pada apa yang Yesus ajarkan dan perintahkan. Oleh sebab itu Yesus mengatakan bahwa siapa pun yang menuruti ajaran dan perintah-Nya berasal dari Allah, mengenal kebenaran Allah, menuruti firman-Nya, dan akan dimerdekakan (Yoh. 8:30-47).

Jika ada pihak yang berpendapat bahwa presuposisi Yesus terlalu subjektif, pandangan seperti ini sepenuhnya keliru. Konstruksi paradigma Yesus harus dimengerti dalam konteks dwi natur-Nya yang justru membuktikan keobjektifan latar belakang pemikiran-Nya. Sebagai manusia sejati, Yesus objektif dalam menggunakan standarstandar Ilahi untuk mendasari rencana dan maksud Allah bagi manusia. Sebagai Allah sejati, Yesus sangat objektif untuk menilai standar-standar kebaikan, cinta kasih, dan keselamatan bagi manusia itu sendiri. Namun jika memang harus demikian, maka Yesus memang subyektif dalam hal menyatakan identitas, kekudusan, dan atribut ke-Allah-anNya, tetapi sangat obyektif dalam menerapkan karya-Nya bagi manusia.

6Philip B. Harner, "The "I am" of the fourth Gospel: A Study in Johannine Usage and Thought," (Philadelphia: Fortress, 1970): 7, dikutip dalam David M. Ball, "Ucapan Yesus "Akulah Dia," dalam Satu Allah, Satu Tuhan: Tinjauan Alkitabiah tentang Pluralisme Agama, Peny. Andrew D. Clarke \& Bruce W. Winter, Terjemahan Martin B. Dainton (Jakarta: BPK Gunung Mulia, 2006), 64. Band. Donald Guthrie, Teologi Perjanjian Baru 1: Allah, manusia, Kristus, 376. 
Bukti-bukti ini menunjukan bahwa ketika Yesus mengajar dan menyampaikan pendapat ke banyak orang, Ia benar-benar perlu membangun dan menggunakan latar belakang pemikiran secara baik dan komprehensif. Yesus tidak sekadar asal bicara tapi Ia telah memperhitungkan banyak hal sebelumnya. Karena itu, banyak orang terkesan dengan pola pikir Yesus, bahkan para lawan-Nya malu dan menyingkir.

\section{Retorika Yesus}

Secara umum diakui bahwa retorika klasik datang dari dunia Greco-Roman. Retorika berkaitan erat dengan sebuah proses komunikasi secara unik untuk meyakinkan pendengarnya mengenai sesuatu. Dori Wuwur Hendrikus memberikan ulasan tentang definisi retorika dalam konteks ini secara baik:

Menurut Socrates, yang juga ahli filsafat, retorika adalah seni untuk membawakan dan menyampaikan pengetahuan yang sudah ada secara meyakinkan. Retorika harus mencari kebenaran dan bukannya mempermainkan kata-kata kosong. Seorang muridnya bernama aristoteles...sangat menghargai retorika sebagai partner yang otonom dari dialektika. ${ }^{7}$

Mengacu pada pemahaman di atas, maka retorika yang baik dalam konteks GrecoRoman mengandung tiga elemen utama yang tidak bisa dipisahkan satu dari yang lain. Ketiga elemen itu adalah ethos, pathos, dan logos. ${ }^{8}$

Ethos merupakan elemen retorika di mana si retor berupaya meyakinkan dan menunjukkan bahwa dirinya adalah sosok yang kapabel dan memiliki kredensi yang dapat dipercaya. Hal-hal yang digunakan untuk menunjukkan kapabilitas dan kredensi diri adalah dengan memperlihatkan kebijaksanaannya dalam menentukan pilihan yang bertujuan baik untuk kebaikan bersama, karakternya yang berkebajikan, dan memiliki kemauan yang baik. Jika retor tidak memenuhi semua atau salah satu elemen tersebut, maka tentu ia bukan seorang retor yang baik dan mampu memper-tanggungjawabkan perkataannya.

Pathos adalah elemen yang harus juga disadari oleh seorang retor. Elemen ini menyangkut keadaan emosional dari setiap orang akan memengaruhi pengambilan keputusan. Kesadaran akan hal inilah yang menuntun seorang retor berupaya mengetahui, memahami, dan kemudian menggunakan hal-hal yang memengaruhi keadaan emosional seseorang untuk mendukung penerimaan terhadap ide-ide si retor sendiri. Kepekaan menjadi syarat untuk dapat menggunakan retorika semacam ini. Sedangkan logos sendiri merupakan elemen yang berhubungan dengan pembuktianpembuktian argumen berdasarkan hukum-hukum logika.

\footnotetext{
${ }^{7}$ Dori Wuwur Hendrikus, Retorika: Terampil berpidato, Berdiskusi, Berargumentasi, Bernegosiasi, cetakan ke-13 (Yogyakarta: Kanisius, 2009), 21

8Penjelasan tentang penggunaan retorika pada bagian ini akan disadur dan dielaborasikan dari Keith A. Reich, Figuring Jesus: The Power of Rhetorical Figures of Speech in the Gospel of Luke (Leiden, The Netherlands: Koninklijke Brill NV, 2011), 3.
} 
Yesus, dalam praktiknya, menggunakan taktik-taktik retoris setiap kali mengajar atau berdialog dengan orang Farisi atau ahli-ahli Taurat. ${ }^{9}$ Saat Yesus mengajar perihal kekuatiran (Mat. 6:25-34; Luk. 12:22-31), Ia menggunakan pendekatan yang retoris. Elemen-elemen retorika yaitu ethos dan pathos Yesus gunakan di sini. Yesus dengan gamblang menyatakan Allah adalah sosok yang memiliki kredensi yang dapat dipercaya untuk memelihara manusia sehingga "janganlah kuatir" (elemen ethos). Yesus juga menggunakan keadaan emosional para pendengarnya seputar perihal kesulitan kebutuhan hidup dan sejarah iman mereka akan penyertaan Tuhan untuk meyakinkan para pendengar tentang "janganlah kuatir" (elemen pathos).

Injil Sinoptik juga menunjukkan bagaimana Yesus dalam banyak kesempatan, mengajar dengan menggunakan perumpamaan. Saya setuju dengan Norman L. Geisler dan Patrick Zukeran yang berpendapat bahwa Yesus beretorika terhadap para audiens baik para murid-Nya atau pun para okhlos melalui perumpamaan-perumpamaan. ${ }^{10}$ Yesus tidak hanya menyatakan kebenaran dan identitas ke-Ilahi-an-Nya melalui perumpamaan (logos) tetapi juga menggunakan perumpamaan-perumpamaan tersebut untuk meyakinkan dan mengajak para audiens untuk memberikan respons terhadap perumpamaan-Nya (ethos dan pathos). Selain itu, ciri-ciri pengajaran yang Yesus sampaikan menggunakan retorika tampak dalam berbagai bentuk gaya bahasa yang terkandung di dalamnya.

Salah satunya adalah "perumpamaan tentang anak yang hilang" (Luk. 15:11-32). Bentuk polyptoton digunakan oleh Yesus dalam perumpamaan ini. Gaya bahasa ini digunakan dalam pembicaraan di mana si pembicara mengubah "kasus" dari kata tertentu yang disebutkan. ${ }^{11}$ Alkitab TB LAI memang tidak memberikan petunjuk yang lebih jelas mengenai hal ini. Namun dalam bahasa Yunani akan menjadi lebih jelas. Pada perumpamaan tersebut, Yesus menggunakan gaya bahasa ini pada term "Bapa" atau

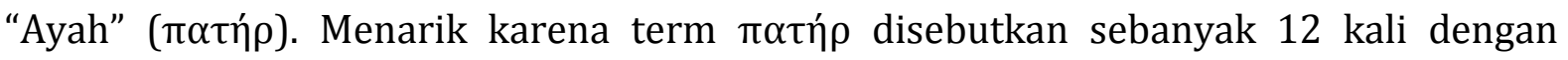

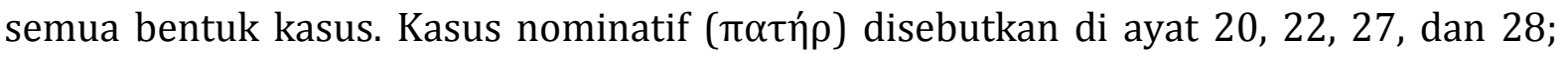
kasus genitif ( $\pi \alpha \tau \rho o ́ \varsigma)$ disebutkan di ayat 17; kasus datif ( $\pi \alpha \tau \rho i ́)$ disebutkan di ayat 12 dan 29; kasus akusatif ( $\pi \alpha \tau \varepsilon \dot{\varepsilon} \rho$ ) disebutkan pada ayat 18 dan 20; sedangkan kasus vokatif ( $\pi \alpha ́ \tau \varepsilon \rho)$ disebutkan pada ayat 12, 18, dan 21. Berbeda dengan penekanannya pada term "anak" yang hanya disebutkan 8 kali dalam dua kasus berbeda. Penggunaan gaya bahasa ini, menurut Reich, "to emphasize the loving father in this parable, and thus to enhance the clarity of his message of God's love."12 Jadi, Yesus menggunakan gaya bahasa retorika untuk menekankan elemen ethos dan pathos mengenai cinta Allah kepada manusia.

\footnotetext{
${ }^{9}$ Lukman Tambunan, Khotbah dan Retorika: Peranan Retorika dalam Penyampaian Firman (Jakarta: BPK Gunung Mulia, 2010), 44-45.

${ }_{10}$ Norman L. Geisler dan Patrick Zukeran, The Apologetics of Jesus, A Caring Approach to Dealing with Doubters (Grand Rapids, Michigan: Baker Books, 2009), 79.

${ }^{11}$ Reich, Figuring Jesus: The Power of Rhetorical Figures of Speech in the Gospel of Luke , 17.

12Ibid, 53.
} 
Yesus bahkan menggunakan gaya bahasa prosopopoiia untuk memberikan penekanan pada bagian tertentu dalam sebuah perumpamaan dengan menciptakan karakter tertentu yang sama untuk mengidentifikasi seseorang yang diumpamakan. ${ }^{13}$ Tujuannya agar perumpamaan tersebut menjadi lebih menarik dan hidup sehingga para pendengarnya tergerak untuk memperbaiki pola pikir mereka. ${ }^{14}$ Misalnya, saat Yesus memberikan perumpamaan tentang "orang kaya yang bodoh" (Luk. 12:16-21) dan “orang-orang yang berdalih" (Mat. 22:1-10; Luk. 14:15-24).

Penggunaan gaya bahasa apostrophe tampak saat Yesus memberikan kecaman kepada orang-orang Farisi dan ahli-ahli Taurat (Mat. 23:1-36; Luk. 20:45-52). Apostropheadalah gaya berbicara yang menunjukkan keadaan emosional (misalnya marah, sedih, atau senang) dengan tujuan menimbulkan efek pada para pendengar. ${ }^{15}$ Yesus menggunakan frase oúaì ùnu (celakalah kamu) secara berulang-ulang sebanyak 6 kali di Matius 23:15-16, 23, 25, 27, 29 dan 5 kali di Lukas 11:42-44, 47, 52. Yesus menggunakan gaya bahasa ini untuk mengalihkan pembicaraan-Nya dari orang banyak kepada orang-orang Farisi secara spesifik. Penekanan yang berulang-ulang tersebut dilakukan oleh Yesus agar orang banyak yang juga hadir dalam peristiwa tersebut memahami apa yang Yesus maksudkan. ${ }^{16}$ Bahkan gaya bahasa dalam mengulang frasa atau kata berulang-ulang secara berurutan adalah jenis Anaphora yang termasuk "bentuk-bentuk kemampuan berbicara/berpidato" (figure of speech) dalam retorika". ${ }^{17}$

Jenis gaya bahasa retorika lainnya yang dapat ditemukan dalam pengajaranpengajaran Yesus adalah Klimaks. Gaya bahasa ini terjadi saat seorang pembicara memberikan peningkatan dalam kata/kalimat argumentasinya setelah kata/kalimat sebelumnya selesai dipaparkan. ${ }^{18}$ Yesus menggunakan cara ini saat berbicara tentang klimaks dari penerimaan atau penolakan terhadap para murid-Nya adalah sama dengan menerima atau menolak-Nya dan menerima atau menolak-Nya sama dengan menerima atau menolak Allah (Mat. 10:40; Mrk. 9:37; Luk. 10:16; Yoh. 13:20).

Yesus dalam berdebat atau berdiskusi dengan para lawan-Nya memakai jenis aporia yaitu dengan mengajukan pertanyaan kepada atau meminta saran dari para audiens seolah-olah tidak tahu apa-apa atau bingung tetapi kemudian memakai cara tersebut untuk memenangkan perdebatan. ${ }^{19}$ Ciri khas saat Yesus menggunakan aporia adalah dengan mengajukan pertanyaan-pertanyaan retoris. Misalnya di dalam Matius 9:5, Markus 2:9, Lukas 5:23 yang merujuk pada peristiwa yang sama di mana Yesus melontarkan pertanyaan retoris sebagai respons terhadap pertanyaan dari orang Farisi.

\footnotetext{
13Ibid, 71-72.

14 Ibid, 73.

15Ibid, 9.

16Ibid, 59-60.

17Ibid, 8.

18Ibid, 65.

19Ibid, 88-89.
} 
Atau, contoh-contoh yang lain seperti pertanyaan retoris Yesus kepada ahli-ahli Taurat dan orang Farisi saat menyembuhkan orang sakit pada hari Sabat (Mat. 12:11-12; Mrk. 3:4; Luk. 6:9; 13:15-16; 14:3-5); saat menjawab pertanda murid-murid Yohanes dan atau orang-orang Farisi tentang keharusan berpuasa (Mat. 9:15; Mrk. 2:19; Luk. 5:34); dan saat mengklarifikasi kuasa yang Yesus miliki untuk mengusir setan (Mat. 12:25-27; Mrk. 3:23; Luk. 11:18-19). Pertanyaan-pertanyaan retoris yang Yesus ajukan tersebut selalu mengajak dan mengubah pola pikir para audiens-Nya untuk terlibat aktif dalam percakapan atau diskusi sehingga pada akhirnya menyetujui apa yang Yesus paparkan.

Ciri khas berikut adalah mengajukan pertanyaan yang bersifat hypophora. Pertanyaan hypophora dilakukan dengan cara mengajukan kembali pertanyaan dari lawan atau diri sendiri dan kemudian memberikan jawaban yang seharusnya atau tidak seharusnya disampaikan. Tujuannya agar posisi sendiri menjadi benar dan lawan menjadi salah atau dengan kata lain membungkam para lawan dalam berargumen dan menyinggung kepentingan penonton, mengundang partisipasi mereka, serta akhirnya mendapatkan kekaguman mereka. ${ }^{20}$

Contoh yang jelas dari Yesus adalah saat berbicara tentang hubungan Mesias dengan raja Daud (Mat. 22:42-45; Mrk. 12:35-37; Luk. 20:41-44). Saat menjawab pertanyaan imam-imam kepala, ahli-ahli Taurat, dan para tua-tua tentang asal-muasal kuasa yang Yesus miliki (Mat. 21:23-27; Mrk. 11:27-33; Luk. 20:4-7). Atau, saat Yesus menjawab pertanyaan ahli-ahli Taurat dan imam-imam kepala tentang keharusan membayar pajak kepada kaisar (Mat. 22:15-21; Mrk.12:13-17; Luk. 20:20-25). Kepandaian Yesus dalam menggunakan hypophora yang dapat berupa pertanyaan tekateki tersebut akhirnya membuat mereka heran, dilematis, tidak lagi dapat berargumentasi dengan Yesus, dan pergi meninggalkan-Nya (Mat. 22:22; Mrk. 12:17; Luk. 20:26).

Selain contoh-contoh di atas, ada juga jenis lainnya yang digunakan Yesus, yaitu 1) atithesis atau "gaya bahasa pertentangan" (Mat. 23:2-4; Luk. 11:39-40; 12:56-57), 2) metaphor atau "gaya bahasa ungkapan tidak langsung yang berupa perbandingan analogis" (Mat. 5:13-16; 15:26; Mrk. 7:27; Luk. 13:32). Apakah dengan beretorika maka Yesus tidak jauh beda dengan kaum sofis? Perlu dicatat bahwa aksentuasi penggunaan retorika oleh Yesus di sini justru ditujukan untuk menyampaikan kebenaran yang terkandung dalam setiap ajaran-Nya. Douglas Estes dalam penelitiannya tentang The Questions of Jesus in John berpendapat, "Both the monologue and the use of questions are logical and make good rhetorical sense, especially if we allow the questions to be questions. "21Karena itu, pengajaran-Nya berisi argumen-argumen yang valid meskipun disampaikan dalam kerangka retorika.

${ }^{20}$ Ibid, 98-99.

${ }^{21}$ Douglas Estes, The Questions of Jesus in John: Logic, Rhetoric and Persuasive Discourse (Leiden: Brill, 2013), 74. 


\section{Pembahasan}

\section{Teknik Propaganda Yesus}

Propaganda dalam penelitian ini merujuk pada definisi dan penggunaanya dalam strategi berkomunikasi. Menurut Nathaniel dan Hans, "Propaganda adalah setiap strategi untuk menyebarkan kepercayaan dan gagasan kita." 22 Untuk itu dibutuhkan metode yang tepat dan jujur agar teknik propaganda yang digunakan tidak manipulatif dan buruk. Moeryanto Ginting Munthe memperjelasnya dengan berpendapat:

Pada dasarnya suatu propaganda sebagai bagian dari kegiatan komunikasi seharusnya merupakan "symbolic interaction" dengan menggunakan lambanglambang komunikasi yang penuh arti, yaitu: bahasa (lisan dan atau tulis), gambargambar, tandatanda, isyarat-isyarat, dan telah dirumuskan/di-encode sedemikian rupa sehingga dapat merangsang jiwa komunikan untuk menerima pesan dan kemudian memberikan reaksinya yang pada akhirnya menumbuhkan efek atau hasil seperti yang telah direncanakan atau ditetapkan oleh komunikator. Dalam hubungan dengan symbolic interaction, kegiatannya bersifat kejiwaan atau psikologis. $^{23}$

Yesus menggunakan pola yang sama dalam mengajar dan berargumentasi. Ia menggunakan propaganda secara positif di dalam menyebarkan ajaran-Nya dengan baik dan cerdas. Kecerdasan-Nya membuat orang-orang bertanya-tanya bagaimana Yesus memperoleh pengetahuan tersebut. Dalam waktu yang singkat, Yesus telah menyebarkan pengaruh yang besar dan luas di Israel dan sekitarnya. Semua orang yang mengikuti-Nya (dengan maksud baik atau tidak) tertarik dengan diri-Nya. Hanya, perlu diingat bahwa tidak selamanya Yesus adalah seorang yang propagandis. Ada hal-hal tertentu yang Yesus tetapkan dengan tegas untuk tidak diberitakan kepada banyak orang.

Alkitab mencatat bahwa berulang kali Yesus juga melarang para murid atau orangorang tertentu bahkan roh-roh jahat untuk memberitakan dengan luas tentang apa yang telah Ia perbuat atau siapa diri-Nya (Mat. 12:16; 16:20; Mrk. 3:12; 5:43; 8:30; Luk. $4: 41 ; 5: 14 ; 8: 56 ; 9: 21)$. Jacob van Bruggen senada dengan itu ketika menulis dalam bukunya, "Ternyata Yesus melarang propaganda seperti itu (3:12). Berkali-kali Dia melarang mereka memberitahukan siapa Dia. Kita keliru bila larangan itu kita tafsirkan sebagai upaya menyembunyikan identitas."24

Jelas bahwa Yesus memiliki kesadaran untuk mengetahui cara dan waktu yang tepat dalam meyakinkan orang lain tentang siapa diri-Nya. Yesus tidak menghendaki adanya propaganda yang hanya melibatkan perasaan emosional semata dari mereka

\footnotetext{
${ }^{22}$ Nathaniel Bluedorn dan Hans Bluedorn, The Fallacy Detective, edisi kedua, terjemahan Ma Kuru Paijo (Kupang: t.p., 2013), 119.

23Moeryanto Ginting Munthe, "Propaganda dan Ilmu Komunikasi", Ulitma Comm: Jurnal Ilmu Komunikasi, volume II, no. 2 (Desember 2010): 46-47.

${ }^{24} J a k o b$ van Bruggen, Markus: Injil Menurut Petrus, Terjemahan Dr. Th. van den End (Jakarta: BPK Gunung Mulia, 2006), 124.
} 
yang mengalami mukjizat agar orang lain ikut terpengaruh untuk percaya tentang diri dan ajaran-Nya. Apalagi jika itu justru berasal dari roh-roh jahat meskipun merupakan kesaksian yang benar tentang-Nya.

Yesus tetap memberikan batasan dalam penyingkapan diri-Nya atau kebenaran yang Ia nyatakan semasa hidup-Nya. Ia tidak selalu menyatakan maksud dari sesuatu kepada semua orang karena Ia tahu hati dan pikiran mereka. Yesus hanya mempercayakan rahasia-rahasia tersebut kepada para murid-Nya yang kelak akan menjadi saksi-saksi hidup tentang diri-Nya. Di samping itu, bukti bahwa Yesus menggunakan teknik propaganda dengan benar dan tidak bermanipulasi dapat disimak dari ulasan singkat di bawah ini.

Pertama, pesona diri Yesus tidak muncul hanya karena kemampuan-Nya dalam meyakinkan orang tetapi juga karena tindakan-tindakan kasih-Nya yang nyata. Yesus tidak berpropaganda hanya dengan seni berbicara indah yang membangkitkan perasaan emosional atau menggunakan elemen pathos para pendengar-Nya. Ia juga mendasarkan dan memberikan bukti-buktinya melalui tindakan dan keteladanan-Nya.

Kedua, Yesus juga tidak menghendaki kedatangan orang banyak karena ikut arus sehingga terjebak dalam bingkai propaganda yang manipulatif. Yesus lebih menghendaki mereka tidak sekadar datang dan mengikuti ke mana pun Ia pergi tetapi juga memiliki iman yang teguh. Di sisi lain Yesus justru berulang kali menekankan agar tidak melakukan sesuatu begitu saja karena ikut arus (bandwagon) terhadap pengaruh dari orang lain. Misalnya, saat Yesus mengajarkan perihal memberi sedekah, Yesus mengajarkan agar tidak mengikuti pola kebiasaan dari "orang-orang munafik" pada umumnya yang berlaku saat itu (Mat. 6:2). Atau, saat mengajar perihal berdoa (Mat. 6:5), Ia juga menekankan pentingnya untuk tidak mengikuti kebiasaan orang-orang munafik pada umumnya. Jelas di sini bahwa Yesus tidak menghendaki adanya propaganda yang didasarkan pada kebiasaan banyak orang yang salah.

Ketiga, beberapa pihak mungkin berpendapat bahwa Yesus melakukan propaganda yang "merujuk pada rasa takut" dan "eksigensi" (terbatasnya waktu) sebagai alasan satu-satunya agar orang-orang yang di sekitar-Nya lebih percaya dan Injil yang Ia beritakan. Misalnya saat Yesus menyerukan agar orang-orang harus bertobat dan percaya pada Injil sebab waktunya telah genap dan kerajaan soga sudah dekat (Mat. 4:17; Mrk. 1:15). Atau, saat Yesus berbicara tentang penderitaan dan siksaan yang akan dialami oleh murid-murid-Nya (Mat. 24:3-28; Mrk. 13:3-23, 33-37; Luk. 21:7-18). Yesus tidak bermaksud menggunakan perasaan takut mereka akan akibat-akibat yang akan mereka alami di masa yang akan datang sebagai alasan-alasan agar mereka pada akhirnya percaya dan mengikuti-Nya.

Ini bukan propaganda manipulatif tetapi perintah, peringatan, dan nubuat Yesus yang harus dilakukan dan akan benar-benar terjadi (Yoh. 3:16-18, 36). Ia memberi pilihan untuk melakukan atau tidak melakukan apa yang Ia perintahkan. Ini adalah 
pilihan dan bukan propaganda yang memanfaatkan rasa takut. ${ }^{25}$ Menarik, karena Yesus justru berjanji untuk tetap menyertai, menolong para murid dan orang-orang, dan menjanjikan hidup kekal karena kesetiaan mereka saat menghadapi seluruh penderitaan (Mat. 24:13, 22; Mrk. 13:13, 20; Luk. 21:18-19).

\section{Konsistensi Yesus: Logis dan Praksis}

Pertama-tama yang perlu dipahami adalah bahwa konsistensi di sini dinilai dari sejauh mana seseorang menggunakan prinsip dan aksioma logika, serta memiliki komitmen yang tinggi untuk tetap pada pendiriannya dan melakukan apa yang dikatakannya sendiri. Lalu, bagaimana dengan Yesus? Di bawah ini adalah beberapa usulan yang dapat dipertimbangkan untuk menjawabnya.

Pertama, Yesus menggunakan hukum-hukum logika secara konsisten dalam berbagai jenis pengajaran-Nya. Aksioma-aksioma logika tersebut dikenal dengan sebutan hukum-hukum logika (The laws of Logic). Hukum-hukum ini bersifat universal, mendasar, benar, dan tidak dapat disangkal. ${ }^{26}$ Karena itu, logika berlaku universal dan tunggal untuk semua bidang ilmu pengetahuan termasuk teologi. ${ }^{27}$ Hukum logika yang dimaksudkan di sini adalah hukum-hukum logika yang dicetuskan oleh Aristoteles, yaitu hukum identitas (law of identity), hukum tidak ada jalan tengah (law of excluded middle), dan hukum kontradiksi (law of contadiction). Hukum yang terakhir ini biasa juga disebut dengan hukum non-kontradiksi (law of non-contradiction). Saya akan menjelaskannya secara singkat di bawah ini.

Hukum identitas (law of identity) diartikan secara simbolis yaitu A berimplikasi A. Artinya, hukum penalaran ini menyatakan identitas dari sesuatu sebagai sesuatu itu, batu sebagai batu, air sebagai air. Kata lainnya, hukum identitas menyatakan bahwa “...kalau satu pernyataan benar, maka pernyataan itu benar; atau, setiap proposisi berimplikasi/berarti dirinya sendiri...."28Yesus menggunakan Hukum Identitas dalam banyak pengajaran-Nya. Bahkan seluruh perkataan dan pengajaran Yesus mengandung hukum ini. Jika tidak demikian maka kata apa pun yang dimaksudkan oleh Yesus bisa berarti apa saja atau tidak memiliki arti apa pun.

Misalnya saat Yesus berkata, "Berbahagialah orang yang takut akan Tuhan" maka yang Ia maksudkan adalah "benar-benar sebuah perasaan damai, senang, dan sukacita patut dirasakan oleh seseorang yang takut kepada Tuhan." Bukan sebuah perasaan lain yang dirasakan oleh jenis orang yang lain. Geisler dan Zukeran berpendapat, "He knew that without this principle we could not even think or talk coherently. For were the

\footnotetext{
${ }^{25}$ Pembahasan tentang argumen yang tidak termasuk sesat pikir "merujuk pada rasa takut", lih. Nathaniel Bluedorn dan Hans Bluedorn, The Detective Fallacy, 124.

26Elihu Carranza, Logic Primer (Napa, California: Inky Publication: 2012), 1.

${ }^{27}$ Clark dengan tegas membantah adanya teori tentang jenis logika yang berbeda-beda untuk setiap jenis ilmu yang berbeda pula dan menganggapnya sebagai penyangkalan terhadap logika itu sendiri. Lih., Gordon H. Clark, Logika, Terjemahan Ma Kuru (Kupang: Pelangi Kasih Ministry, 2014), iv.

28Elihu Carranza, Logic Primer, 2.
} 
principle of identity not true, then God could mean not God; believe could mean not believe, and good could mean not good."29

Implikasinya, jika sebuah kata bisa berarti apa saja atau tidak memiliki arti yang pasti maka kata tersebut tidak berarti sama sekali. Yesus memperhatikan implikasi ini dengan sangat baik. Salah satu perkataan atau ajaran Yesus yang paling terkenal untuk menggambarkan bagaimana Ia menggunakan hukum ini secara ketat adalah perkataanNya yang terdapat di dalam Matius 5:37. Pada ayat ini Yesus dengan tegas menegaskan tentang identitas dari "Ya" hendaklah katakan "Ya" dan "Tidak" hendaklah katakan "Tidak". Kata lainnya, "Ya" diidentifikasi sebagai "Ya" dan "Tidak" diidentifikasi sebagai "Tidak". Dengan demikian, setiap kata dan kalimat yang Yesus gunakan untuk mengidentifikasi sesuatu sebagai atau bukan sesuatu merupakan bukti bahwa Ia secara keseluruhan menggunakan hukum Identitas.

Hukum tidak ada jalan tengah (law of excluded middle). Hukum penalaran ini secara simbolis ditulis A atau non-A. Hukum ini menyatakan bahwa sesuatu sebagai ini atau itu, batu haruslah keras atau tidak keras, Alkitab haruslah firman Allah seutuhnya atau bukan firman Allah seutuhnya. Yesus juga menggunakan Hukum Tidak Ada Jalan Tengah. Penekanannya bahwa "This is a precondition of every thought Jesus expressed, since no affirmation (or negation) can be true and false simultaneously in the same sense."30 Penggunaan hukum ini oleh Yesus dapat dilihat saat Ia berkata. "Siapa tidak bersama Aku, ia melawan Aku dan siapa tidak mengumpulkan bersama Aku, ia mencerai-beraikan." (Mat. 12:30; Luk. 11:23). Yesus menggunakan hukum ini untuk menegaskan bahwa tidak ada sikap yang netral dalam mempercayai dan mengikutiNya. Maksudnya, Yesus menyatakan bahwa tidak ada pilihan untuk percaya sekaligus tidak percaya pada-Nya, mengikuti sekaligus tidak mengikuti-Nya. Jika tidak menerimaNya berarti konsekuensinya adalah menolak-Nya; tidak bersama-sama dengan-Nya berarti melawan-Nya begitu pula sebaliknya.

Hukum non-kontradiksi (law of non-contradiction) disimbolkan dengan A dan nonA. Hukum ini menegaskan bahwa sesuatu tidak mungkin A dan bukan A pada saat yang bersamaan dan hubungan yang sama pula. Suatu pernyataan yang mengandung salah dan benar sekaligus adalah suatu kontradiksi. Norman L. Geisler dan Patrick Zukeran berpendapat bahwa sesungguhnya,"This principle states that it is impossible that contradictory statements be simultaneously true in the same sense. If one statement is true, its contradiction is necessarily false."31 Misalnya, saat Yesus membedakan nabi yang palsu dari yang benar (Mat. 7:15; 24:24; Mrk. 13:22), Yesus membedakan menjadi dan hidup dalam terang dengan menjadi dan hidup dalam kegelapan (Mat. 6:23; Luk. 11:35; Yoh. 8:12; 12:46), Yesus menegaskan perihal perbedaan pengabdian kepada Allah dan kepada Mamon (Mat. 6:24; Luk. 16:13), atau memberikan kontradiksi yang tajam antara

\footnotetext{
${ }^{29}$ Geisler dan Zukeran, The Apologetics of Jesus, A Caring Approach to Dealing with Doubters, 69.

30Ibid, 70.

31Ibid, 69.
} 
mereka yang berasal dari Allah dan yang berasal dari iblis (Yoh. 8:42-47), Ia menggunakan Hukum non-kontadiksi. Perlu diingat bahwa hukum ini mencakup kedua hukum sebelumnya. Oleh karena Hukum Tidak Ada Jalan Tengah dan bahkan Hukum Identitas itu sendiri berlaku di seluruh bagian pengajaran Yesus secara konsisten, maka Hukum Non-Kontradiksi juga dapat berlaku di sana secara konsisten. Jadi, Yesus sangat konsisten dalam menggunakan hukum-hukum penalaran ini.

Kedua, Yesus menggunakan banyak bentuk penalaran dalam berargumentasi secara konsisten. Namun dalam bagian ini saya hanya memaparkan dua bentuk penalaran yang Yesus gunakan, yaitu: argumen a fortiori dan reductio ad absurdum. ${ }^{32}$ Kitab-kitab Injil memberikan data yang sangat banyak mengenai penggunaan argumentasi A Fortiori oleh Yesus. Argumentasi ini secara singkat berarti bahwa jika A benar dan bukti untuk B lebih kuat dari bukti untuk A, maka B harus diterima sebagai benar.

Yesus menggunakan argumentasi ini dalam pengajaran-Nya tentang hal kekuatiran di mana Ia menyatakan bahwa jika burung-burung di langit dipelihara Allah, jika bunga bakung dan rumput-rumput di dandani Allah, betapa lebih berharga manusia di mata Allah karena itu janganlah kuatir (Mat. 6:25-34; Luk. 12:22-31). Yesus juga menggunakan saat berargumentasi dengan orang-orang Farisi dan ahli-ahli Taurat soal menyembuhkan orang pada hari Sabat (Mat. 12:11-12; Luk. 13:10-16; Yoh. 7:21-23). Dalam hal ini, Yesus menyatakan dalam setiap kesempatan yang berbeda bahwa jika menangkap dan menyelamatkan domba yang terjatuh ke lubang, membawa lembu dan keledai untuk minum, serta melakukan sunat dapat dilakukan pada hari Sabat, apalagi menyembuhkan dan menyelamatkan seorang manusia pada hari Sabat.

Begitu pula saat berbicara tentang pengabulan doa (Mat. 7:11) dan dalam perumpamaan tentang seorang hakim yang membela perkara seorang janda sebagai analogi pembanding tentang apa yang akan Allah lakukan lebih lagi untuk membenarkan dan menolong umat-Nya (Luk. 18:2-8), Yesus menggunakan argumentasi ini. Contoh-contoh yang lain sangat berlimpah di dalam kitab-kitab Injil (Luk. 11:11-12; 12:4-5, 6-7, 24, 27-28, 54-56; 14:1-5; 18:1-8).

Selanjutnya, Yesus menggunakan reductio ad absurdum saat berargumentasi dengan orang-orang Farisi tentang kuasa apa yang Yesus gunakan untuk menyembuhkan seorang yang kerasukan setan (Mat. 12:22-37). Pertama-tama Yesus menggunakan proposisi yang orang Farisi pakai yang menuduh-Nya menggunakan kuasa setan untuk mengusir setan. Ia lantas menyatakan bahwa jika kuasa setan yang Ia gunakan, maka itu berarti setan mengusir dan menghancurkan kerajaannya sendiri (ay. 25-26). Kedua, Yesus juga berpendapat bahwa para pengikut Farisi lainnya juga pernah

\footnotetext{
${ }^{32}$ Redutio Ad Absurdum (reduksi yang absurd) adalah sebuah argumen yang menyatakan bahwa jika sesuatu seharusnya benar tetapi justru mengarah pada adanya kontradiksi atau absurditas, maka sesuatu itu tidak dapat dikatakan benar, lih.: Ibid., 75.
} 
mengusir setan dan mereka dipercaya menggunakan kuasa Allah untuk sanggup melakukan tindakan tersebut (ay. 27).Lalu, Yesus menyimpulkan dengan apik bahwa mereka seharusnya percaya akan kuasa yang Ia gunakan juga berasal dari Allah (ay. 2728). Dengan demikian, "Jesus uses the reductio ad absurdum argument to show that the claim that his authority to cast out demons is from Satan creates a contradictory and absurd conclusion."33 Yesus sangat brilian dalam bagian ini.

Ketiga, Yesus memberikan keteladanan tidak hanya dari perkataan tetapi juga tindakan secara konsisten. Yesus tidak hanya menunjukkan bahwa Ia konsisten dalam hal pengajaran tetapi secara praksis diterapkan melalui moralitas-Nya.Jika Yesus mengajarkan kasih dan mengasihi tetapi Ia sendiri memilih untuk tidak menolong dan menyembuhkan seseorang bahkan jika itu pada hari Sabat, maka tentu Ia tidak konsisten secara logis.

Kenyataannya, Yesus tidak hanya sekadar mengajarkan tetapi juga bertindak dengan kasih. Misalnya, Yesus pada satu kesempatan mempersilakan para murid untuk membawa pedang (Luk. 22:36), tetapi itu tidak berarti Yesus memerintahkan mereka untuk berbalik membenci para musuh dan membunuh dengan pedang atau Ia sendiri terlibat dalam suatu aksi pembunuhan sehingga Ia menjadi tidak konsisten dengan perintah-Nya tentang kasih dan larangan menggunakan pedang. T.W. Manson memberikan pendapat yang menarik tentang ini:

Jesus must be consistent: he must have the same message in much the same terms for everyone. Above all he must be a popular teacher whom the common people hear gladly, because his message is so simple that all can understand it. As an ethical teacher 'he contends for the weightier matters in the law, for the common morality which sees its aim in the furtherance of the well-being of others, and which commends itself at once to the heart of everyone.' ${ }^{34}$

Yesus juga memang berbicara tentang kedatangan-Nya membawa pedang dan permusuhan di mana Yesus mengingatkan para murid dan orang-orang percaya bahwa mereka akan mengalami penderitaan dan aniaya dari para penguasa suatu kelak nanti. Namun itu tidak berarti bahwa pada saat yang bersamaan Ia tidak memberikan damai sejahtera dan sukacita bagi para pengikut-Nya. Yesus justru memberikan damai sejahtera dan mengutus Roh Kudus sebagai penghibur dan penuntun orang percaya untuk menghadapi penderitaan karena iman mereka.

Di satu sisi, Yesus memiliki dan menggunakan intelektual-Nya secara ketat logika. Ketika Ia mengajar dan berargumen dengan orang-orang, Yesus tidak mengesampingkan pentingnya menggunakan bentuk penalaran yang logis dan valid. Itu tidaklah mengherankan sebab, "kemampuan-kemampuan dan pencapaian-pencapaian intelektual-Nya di dunia berakar di dalam Tuhan yang mahatahu, mahahadir, dan

33Ibid, 76.

${ }^{34}$ T.W. Manson, The Teaching of Jesus, Studies in Its Form and Content (Cambridge: Cambridge University Press, 1967), 16. 
mahakuasa." 35 Di sisi lainnya, Yesus juga memberikan pengajaran melalui pemberian teladan dan contoh bagi para rasul dan orang-orang lain. Konsistensi Yesus tidak hanya tampak dalam kata-kata tapi juga implementasinya pada perbuatan.

\section{Kesimpulan}

Pembuktian-pembuktian ini memberikan sumbangsih besar bagi pemahaman tentang bagaimana Yesus mendasari dan mengungkapkan pendapat-Nya. Saat Ia menjawab pertanyaan lawan, mengajukan argumen-argumen, mengubah alur diskusi, mengajak orang lain untuk percaya dan mengikut-Nya, menyingkapkan dan mengajarkan tentang kebenaran, Yesus benar-benar menyusun dan menyampaikan semua itu dengan apik. Kecakapan-Nya dalam membangun presuposisi, menggunakan retorika yang baik untuk menyampaikan pemikiran-Nya, mempropagandakan pengajaran-Nya secara positif, menggunakan hukum-hukum pemikiran yang ketat logika, serta konsistensi yang selaras antara ucapan dan perbuatan sudah tidak diragukan lagi.

Yesus tidak sekadar menyampaikan pendapat di muka umum tanpa latar belakang pemikiran yang jelas. Ia juga menggunakan argumen yang valid dan benar serta metode yang selalu kontekstual, sesuai kepada siapa Ia berbicara. Paradigma dan metode seperti ini seharusnya dapat dijadikan sebuah model pembelajaran bagi para akademisi. Pengungkapan pendapat yang efektif dan efisien seharusnya dimulai dengan sebuah dasar pemikiran yang sehat, kemudian dituangkan dalam sebuah opini yang memenuhi unsur validitas dan soundness. Dan tentu saja, penyampaian pendapat juga harus bebas dari cara-cara yang bertujuan untuk memanfaatkan situasi-mendapat keuntungan sendiri tanpa memperdulikan aspek kebenaran yang hakiki.

\section{Referensi}

Baker, David L. Mari Mengenal Perjanjian Lama. Jakarta: BPK Gunung Mulia, 2008. Bertens, K. Sejarah Filsafat Yunani, edisi revisi, Cet.ke-25. Yogyakarta: Kanisius, 2011. Bluedorn, Nathaniel \& Hans Bluedorn. The Fallacy Detective, edisi kedua. Terjemahan Ma Kuru Paijo. Kupang: t.p., 2013.

Carranza, Elihu. Logic Primer. Napa, California: Inky Publication: 2012.

Clark, Gordon H. Logika. Terjemahan Ma Kuru. Kupang: Pelangi Kasih Ministry, 2014. Clark, Gordon H. Thales to Dewey: A History of Philosophy, Ed.ke-4. Unicoi, TN: Trinity Foundation, 2000.

Clarke, M. L. Rhetoric at Rome, A Historical Survey. London and New York: Routledge, 1996.

Cohn-Sherbok, D. M. "An Analysis of Jesus' Arguments concerning the Plucking of the Grain on the Sabbath". JSNT 2, 1979.

Dokas Alumni STF Driyarkara, "Diskusi Publik: Menolak Pembusukan Filsafat", https://youtu.be/PqQLv7Z3QWM (diakses 06 Maret 2019).

Estes, Douglas. The Questions of Jesus in John: Logic, Rhetoric and Persuasive Discourse. Leiden: Brill, 2013.

35 James W. Sire, Habits Of The Mind: Kebiasaan Akal Budi, Kehidupan Intelektual Sebagai Sebuah Panggilan (Surabaya: Momentum, 2012) 244. 
Frame, John M. "Orang Yunani yang Membawa Hadiah," dalam Revolusi-Revolusi dalam Wawasan Dunia: Memahami Arus Pemikiran Barat, Peny. W. Andrew Hoffecker. Surabaya: Momentum, 20017.

France, R. T. The New International Commentary On the New Testament The Gospel Of Matthew. Grand Rapids, Michigan: William B. Eerdmans, 2007.

Geisler, Norman L. \& Patrick Zukeran. The Apologetics of Jesus, A Caring Approach to Dealing with Doubters. Grand Rapids, Michigan: Baker Books, 2009.

Guthrie, Donald. Teologi Perjanjian Baru 1: Allah, manusia, Kristus. Terjemahan Lisda Tirtapraja Gamadhi, dkk. Jakarta: BPK Gunung Mulia, 2008.

Hadiwijono, Harun. Sari Sejarah Filsafat Barat 1, Cet.ke-26. Yogyakarta: Kanisius, 2010.

Harner, Philip B. "The "I am" of the fourth Gospel: A Study in Johannine Usage and Thought," (Philadelphia: Fortress, 1970): 7, dikutip dalamDavid M. Ball, "Ucapan Yesus "Akulah Dia," dalam Satu Allah, Satu Tuhan: Tinjauan Alkitabiah tentang Pluralisme Agama, Peny. Andrew D. Clarke \& Bruce W. Winter. Terjemahan Martin B. Dainton. Jakarta: BPK Gunung Mulia, 2006.

Hendriksen, William. New Testament Commentary Matthew. Grand Rapids, Michigan: Bakker Academy, 2007. Bakker Academy, 2007.

New Testament Commentary John. Grand Rapids, Michigan:

Hendrikus, Dori Wuwur. Retorika: Terampil berpidato, Berdiskusi, Berargumentasi, Bernegosiasi. Cetakan ke-13. Yogyakarta: Kanisius, 2009.

Jeremias, Joachim. Jerusalem in the Time of Jesus, An Investigation into Economic and Social Conditions during the New Testament Period. Epub version. Philadelphia: Fortress Press, 1969.

Manson, T.W. The Teaching of Jesus, Studies in Its Form and Content. Cambridge: Cambridge University Press, 1967.

Moreland, J.P. and William Lane Craig. Philosophical Foundation for a Christian Worldview. Downers Grove, Illinois: InterVarsity, 2003.

Munthe, Moeryanto Ginting. "Propaganda dan Ilmu Komunikasi”, Ulitma Comm: Jurnal Ilmu Komunikasi, volume II, no. 2 (Desember 2010): 46.

Reich, Keith A. Figuring Jesus: The Power of Rhetorical Figures of Speech in the Gospel of Luke. Leiden, The Netherlands: Koninklijke Brill NV, 2011.

Sire, James W. Habits Of The Mind: Kebiasaan Akal Budi, Kehidupan Intelektual Sebagai Sebuah Panggilan. Surabaya: Momentum, 2012.

Sujoko, Albertus. Identitas Yesus \& Misteri Manusia, Ulasan Tema-Tema Teologi Moral Fundamental. Cetakan ke-5. Yogyakarta: Kanisius, 2013.

Tambunan, Lukman. Khotbah dan Retorika: Peranan Retorika dalam Penyampaian Firman. Jakarta: BPK Gunung Mulia, 2010.

Tim Penyusun. Kamus Bahasa Indonesia. Jakarta: Pusat Bahasa, 2008.

van Bruggen, Jakob. Markus: Injil Menurut Petrus, Terjemahan Dr. Th. van den End. Jakarta: BPK Gunung Mulia, 2006. 